\title{
MULTIPLE CASE SAMPLING OF ECT ADMINISTRATION TO 217 MINORS: REVIEW AND META-ANALYSIS
}

\author{
Baldwin, Steve \\ Oxlad, Melissa \\ Journal of Mental Health. Dec96, Vol. 5 Issue 5, p451-464. 14p. 7 Charts.
}

\section{$\underline{\text { Abstract }}$}

A multiple case sampling framework was used to produce a review and meta-analysis of the published cases of ECT administration with minors. An extensive search of the published literature located 217 minors who had been given ECT treatment between 1947 and 1996. These cases were analysed via demographic data (ie gender, age) and clinical data (ie diagnostic criteria, presenting behaviours, mode of ECT administration, consent, index behaviours, drug therapies, outcomes and side-effects). Three behavioural predictors (PB3) were identified which were associated with an increased likelihood of a minor receiving ECT. Interpretations of the analysis revealed that the data are at variance with psychiatrists' claims that ECT is given as a 'life saving'(sic) treatment for minors. Suicide was mentioned in only $5 \%$ of cases. Some speculative comments are also provided.

\section{$\underline{\text { Introduction }}$}

Since the invention of electroconvulsive therapy (ECT) by Cerletti \& Bini (1940) in 1938 there has been considerable controversy about the indications for this treatment. Parallel debates have continued about effectiveness, efficacy and utility. These debates have continued into the 1990s, whilst administration of ECT/EST (electro-shock treatment) is in a period of contemporary resurgence, in a context of twin clinical foci on cost-effectiveness and outcomes. Advocates of ECT have maintained that it is a highly effective intervention for all populations, including children/adolescents (Abrams, 1988; Fink, 1990). Critics have objected strongly to ECT administration with minors, on clinical, moral, legal, philosophical and ethical grounds.

Until 1947 ECT was used exclusively with adult populations. By the end of the 1940s, however, Bender (1947) and Heuyer et al. (1947) had set a precedent for ECT use with a new target population: children/adolescents. In the United States Bender (1947) published a landmark study which reported data about the administration of ECT to 98 children and adolescents. Also in 1947, Heuyer et al. (1947) published a similar report from a European study; in France, psychiatrists reported data after the administration of ECT to 29 minors. These ground-breaking studies were subsequently highly influential in the development of ECT practices in North America, Europe and Australasia.

After these studies, psychiatrists used ECT with children/adolescents regularly, and for a wider range of mental health problems/index behaviours. ECT became a 'cure-all' treatment for some 
psychiatrists who worked with children/adolescents with mental health problems. As the list of index behaviours was expanded during the 1950s and 1960s, other minors were given ECT.

According to the medical judgement of psychiatrists, indications for ECT included (but were not limited to): schizophrenia; mania; catatonia; eating disorder; mood disorder; thought disorder; Alzheimers disease, intellectual disability and Gilles de la Tourette Syndrome.

Between 1947 and 1996 the use of ECT with children/adolescents has continued. True prevalence rates remain unknown, however, due to restrictions on psychiatrist/client confidentiality, poor/unavailable medical records, and too few cases reported in an alreadymeagre literature. Despite this, a 1994 survey by the UK Royal College of Psychiatrists identified more than 60 cases of ECT administration to minors. Moreover in the USA it has been estimated that ECT is administered to between 500 and 3500 minors each year (Thompson \& Blaine, 1987). Some researchers have suggested that ECT is used currently with children/adolescents as a 'treatment of choice', and not as a 'treatment of last resort' (Oxlad \& Baldwin, 1995). Although psychiatrists have claimed otherwise, ECT seems to be used in the 1990s as a first-line treatment, in conjunction with pharmacological approaches.

The present study was based on a qualitative analysis of documented cases of ECT administration with minors. A multiple case sampling and meta-analysis framework was used to review all published accounts of ECT administration with minors.

\section{Method Design}

The study was aimed to investigate specific questions, based on previous clinical observations about ECT administration to children and adolescents (Baldwin \& Jones, 1990, 1991; Barker \& Baldwin, 1990). First, it was believed that ECT was given as a 'treatment of choice' and not a 'treatment of last resort', and generally when psychotherapy had not been attempted. It was believed that ECT was given in the absence of valid/informed consent and for a non-specific range of presenting behaviours. Moreover it was believed that ECT was given to minors in nonlife-threatening clinical circumstances. These clinical observations were based on the practice of psychiatrists and nurses who had previously administered ECT to minors (Barker \& Baldwin, 1990; Oxlad \& Baldwin, 1995).

\section{$\underline{\text { Procedure }}$}

Silver Platter 3.11, Psych Lit, Medline and Biological Abstracts databases were used to search the literature and locate reported cases of administration of ECT to children/adolescents. The reference lists of already-published cases provided several extra reports not listed in existing databases.

Raw data were documented for each case about: age, sex, presenting behaviours, diagnosis, initial therapies, drug therapies, presence/absence of consent, total number of ECT treatments, mode and duration of treatment, side-effects and outcomes. 'Presenting behaviours' reported in the original papers were coded for each case chronologically. Coding was completed using the nine clinical categories previously established for diagnostic work with children/ adolescents by Achenbach \& Edelbrock (1991): withdrawn; somatic complaints; anxious/depressed; social 
problems; thought problems; attention problems; delinquent behaviour; aggressive behaviour; other problems. Each category from the checklist contained several sub-categories of clinical presentations (i.e. withdrawn: rather be alone; won't talk; shy). The presenting behaviours of the 217 cases were matched to these categories and subcategories and coded accordingly. Reporting methods vary between studies and across time, however. This behavioural checklist has been used extensively in clinical setting s with children and adolescents aged 4-18 years (Achenbach \& Edelbrock, 1991). Data from each case were entered into a 'key table' of presenting behaviors, in chronological order (Miles \& Huberman, 1994).

\section{$\underline{\text { Results }}$}

Summary data are reported for the 217 published cases. A complete reference list for the original papers is provided in Appendix 1.

\section{Demographic data: gender}

In this multiple case sample, ECT was administered to 110 males and 72 females; in 35 cases the sex of the minor was unspecified.

Demographic data: age

All published cases which included children and adolescents aged 18 and under were included in the sample. The age range was 418 years (see Table 1). Where group studies with pooled data were included, one case was entered in the sample, coded at the lowest reported age. Data from the Bender (1947) study were reported separately.

\section{Clinical Data: diagnostic criteria}

In Table 2, diagnostic data are reported. These data (coded via the Achenbach and Edelbrock checklist/profile indicate the relative diagnostic frequencies for which minors were referred for ECT. Bender (1947) data are reported separately.

\section{Clinical data: presenting behaviors (PB)}

Using the Achenbach \& Edelbrock (1991) checklist/profile, each case was analysed to determine the relative frequencies at which presenting behaviours (PB) were recorded. Table 3 provides summary data for frequencies of presenting behaviours.

\section{Clinical data: ECT administration (mode)}

The data in Table 4 provide a summary of the total number of ECT treatments given, and mode of administration (i.e. whether unilateral or bilateral, where specified), broken down by decade. 
In 3 cases, written consent for ECT was obtained from parents 'on behalf of the minor'. Consent was obtained from the minor on 2 occasions. Once both the minor and parents gave consent. No consent was obtained in two instances. In the remaining 209 cases, no data about consent were reported.

\section{Clinical data: index behaviours}

Some common index behaviours were identified in this multiple case sample. Sixty-five data points were recorded in the 'withdrawn' category; of these, 14\% scored for 'won't talk', and 14\% for 'withdrawn'. Within the 'anxious/depressed' category, $17 \%$ scored for 'cries', and 34\% for 'depressed'. Sixteen percent scored on 'hears things' in the 'thought problems' category, 10\% scored for 'paranoia' and $11 \%$ for 'delusions'. In the 'attention problems' category, $19 \%$ scored for 'concentration problems', $23 \%$ for 'agitation' and 23\% for 'hyperactivity'. In the 'aggressive behaviour' category, $21 \%$ scored for 'mood shifts', 13\% for 'affect problems', $10 \%$ for 'catatonic/schizoid problems', 13\% for 'aggressive behaviour' and 16\% for 'talkative behaviour'. In the 'other problems' category, $16 \%$ scored for 'eating disorders' and 13\% for 'sleep disorders'.

\section{Clinical data: drug therapies}

Interpretation of the data in Table 5 indicates the type and frequencies of drug therapies used with children/adolescents before and during ECT administration.

Twenty-six minors did not respond to drug therapy. Examination of the data in Table 6 indicates the type and frequency of drug therapies which were unsuccessful.

Specific drug therapies used with children after ECT administration have included insulin therapy. Although no specific data are available about other post-ECT drug therapies, many of the drugs given to children/adolescents before and during ECT administration have been used later for 'maintenance therapy'. Drugs used for 'maintenance' have included: fluphenazine decanoate injections; lithium carbonate; maprotiline; and trifluoperazine.

\section{Clinical data: summary of outcomes}

Interpretation of the data in Table Seven indicate the outcomes of ECT administration.

\section{Clinical data: side effects after ECT}

Reported side-effects of ECT treatment have included diminished IQ and interference in function immediately after treatment. Visual motor Gestalt performance has showed marked regression to primitiveness immediately after each treatment and perseveration and disorientation of time, place and person have also occurred. Other side-effects have included delayed recall of auditory and visual information and impaired learning below the tenth percentile. Confusion, memory deficit, short-term memory loss, elevated skin temperature and manic symptoms (elevation, disinhibition, over-activity, over-talkative with sexual overtones, amnesia) have also resulted from ECT treatment. Painful headaches, an inability to concentrate and reading problems were common. In some cases it became difficult to make contact with the person, they were unhappy 
and/or frightened, and exhibited compulsive features. In one case the neck and face flushed (ipsilateral to treatment side) and the right eye was described as congested and lacrimating. Most seriously, anoxic brain damage was also recorded.

\section{Discussion Overview}

Some clear clinical conclusions can been derived from these 217 cases. An analysis of the results from this multiple case sample and meta-analysis has provided some preliminary insights about the medical practice of psychiatrists who have administered ECT to minors. As a cross-national sample of clinical cases, it may be representative of the practice of other psychiatrists who have not published the results of their ECT administration with minors.

Chronologically, the Bender (1947) and Heuyer et al. (1947) studies established the 'setting conditions' in the United States and Europe for the subsequent administration of ECT with minors. In the landmark US study with 98 children aged between 4 and 11 years, Bender (1947) pioneered the use of ECT with this new population, with a psychiatric focus on 'childhood schizophrenia'. In France, the Heuyer et al. (1947) study was based on the administration of ECT to 29 minors, aged between 5 and 15 years. The psychiatric focus was much wider in the French study, however, including ECT administration to children with a wide range of clinical presentations (e.g. tics, mutism, mania).

Although few contemporary psychiatrists have reported the use of ECT with quite the same zeal and vigour on minor populations, modem-day enthusiasm for electroconvulsive therapy has continued. Examination of the data-set suggests a scenario of psychiatrists seeking to maintain the possible clinical province of a perceived 'tried and tested' therapy.

\section{$\underline{\text { Gender }}$}

A gender analysis of these documented cases of minors who have been given ECT indicates that more males (51\%) than females $(33 \%)$ have been given this treatment; in $16 \%$ gender was not specified. During the 1980s and 1990s, however, there is some evidence of a contemporary shift to more administration of ECT to girls than boys.

Age

An examination of the ages of minors given ECT revealed a wide range from 4-18 years. Administration of ECT to people in their late teens would not be considered unusual by many staff working in psychiatric departments. Delivery of unknown electric currents to infants, however, would be considered exceptional by most psychiatrists; this practice requires further scrutiny. Although the proportion of infants is small, more than one-third of minors in this study (78/217) was under 10 years. This raises several questions about reasons why psychiatrists administer ECT to very young children. First, although some psychiatrists have claimed benefits from the treatment, there are considerable risks associated with neuro-psychological and/or physical side-effects, when ECT is given to minors. Second, there is no clinical rationale for administration of this unproven technique with children and adolescents. Third, when other 
effective, less-invasive alternative interventions exist, the choice of ECT seems, at best, paradoxical.

The modal age for ECT administration in this multiple case sample was 14.0 years; 39 cases $(18 \%)$ were aged 14 or 15 . If these data are representative of the practice of other psychiatrists, it suggests the use of ECT to resolve developmental adolescent problems. Since the 1960s, published ECT administration with very young minors under ten has been comparatively infrequent.

\section{$\underline{\text { Diagnostic criteria }}$}

About diagnostic criteria, the use of the Achenbach \& Edelbrock (1991) framework allowed a clinical analysis of the profile of minors who were given ECT. In this analysis, the Bender (1947) data were excluded (Bender's cases were clinically indistinguishable: all cases had been given an identical initial diagnosis, based on: withdrawn, anxious/depressed, social problems, thought problems, attention problems and 'other problem' behaviours). Examination of these data indicates that many minors had received a diagnosis based on withdrawn (30), anxious/ depressed (36), thought problems (37) or aggressive behaviour (37). Examination of individual case histories confirmed a clinical picture of minors frequently referred for ECT after an initial psychiatric diagnosis of 'anxiety' (sic) and/or 'depression' and/or 'schizophrenia'.

\section{Presenting behaviour}

Each reported presenting behaviour (PB) of these 217 minors was documented and coded, according to the Achenbach \& Edelbrock (1991) profile. A total of 436 different presenting behaviours was recorded across the sample. Examination of individual cases indicated that some behaviours were very frequently documented across the data-set. (In this analysis, the Bender (1947) data were excluded, as all 98 cases were clinically indistinguishable.) On 112 occasions, thought problems were documented: aggressive behaviour (97), and anxious/depressed behaviours(70) also were frequently reported.

These three presenting behaviour categories (PB3) were further examined, in the search for possible behavioural predictors. An analysis of all published cases showed that $25 \%$ scored in one of the PB3 categories; 35\% scored in two of the PB3 categories; and 33\% scored in all three of the PB3 categories. Thus, two-thirds $(68 \%)$ scored in either two or three of the PB3 categories. Seven percent of cases did not score in any of the PB3 categories. This analysis suggests that if the presenting behaviours of a minor are in one (or more) of the PB3 categories, then specific diagnoses will follow, and the minor is more likely to receive ECT treatment.

If these (PB) data are clinically representative of other non-documented ECT administrations with minors, children and adolescents may be more likely to be considered for ECT if they are: mute, withdrawn, crying, depressed, hearing things, delusional, paranoid, hyperactive, moody, catatonic, aggressive, talkative, and/or if they have an eating/sleep disorder. Co-occurrences of anxious/ depressed behaviour, thought problems and aggressive behaviour will increase the probabilities of ECT administration. 


\section{$\underline{\text { ECT administration -- mode }}$}

Analysis of the data about the delivery of ECT to minors suggests a picture of idiosyncratic application of a technique with unknown and unpredictable effects. Examination of the data confirms that there is no standardised relationship between diagnosis and treatment; in the case sample, six minors were given more than 40 treatments, and 89 were given more than 20 treatments. There is no specified 'course' of ECT; individual psychiatrists administer ECT according to the perceived condition of the child/adolescent. Although some data are available about the mode of administration, there is no clear pattern; psychiatrists have used both bilateral and unilateral ECT administration. Some children/adolescents in the sample were given both unilateral and bilateral ECT. Although many contemporary psychiatrists seem to favour unilateral administration with adults, there is no consistent approach when ECT is given to minors.

\section{$\underline{\text { ECT administration -- consent }}$}

Inspection of these data cannot confirm whether valid or informed consent has been obtained regularly when ECT has been given to minors. Most studies do not mention it; in only 3/217 instances (less than 1\%) was consent by the minor specifically included in the case description. It is unknown whether consent was obtained and not reported, or not obtained and not reported, or both.

\section{$\underline{\text { Index behaviours }}$}

A review of the multiple case sample confirmed a very wide range of index behaviours amongst minors subsequently given ECT. Thus, some index behaviours would be consistent with subsequent psychiatric diagnoses (e.g. presence of psychotic symptoms/hallucinations/paranoid delusions, leading to diagnosis of 'schizophrenia'). The significance of other behaviours is more difficult to interpret in a clinical context (e.g. tearful/unable to relax/giggly/ compulsive exercising/ flighty/jumpy/decrease in school grades/lost concentration/easily distracted/told many lies/ cheerful/glum/spoke out of turn/vague). Some index behaviours in the 'other problems' category at best suggest over-inclusivity (e.g. no weight loss/no weight change/no sleep disturbance/urinary incontinence/grunting/ fear of people/indecisive/frustrated with life/ grimaced/excessive time in the bathroom). The detection of index behaviours linked to intellectual functioning (e.g. mental retardation/highly intelligent) is paradoxical, at least.

The wide range of index behaviours, and the high volume (436) strongly suggests clinical imprecision amongst psychiatrists. Analysis indicates that a form of 'net-widening' (McMahon, 1990) has occurred in this situation, where a too-wide range of behaviours have been viewed as pathological or dysfunctional. Examination of these raw index behaviour data confirms the impression that psychiatrists have recommended ECT to minors whose behaviours are within the range of normal development.

\section{Drug therapies}


Analysis of drug therapies given to children/adolescents before and during ECT administration has identified several frequently prescribed drugs. Two percent of minors received antihypertensives; hypnotics $6 \%$; anxiolytics $0.6 \%$; anti-psychotics $42 \%$; anti-depressants $41 \%$; anticonvulsants $1 \%$; drugs for movement disorders $4 \%$; CNS stimulants $0.6 \%$; migraine treatments $0.6 \%$; general anaesthetics $0.6 \%$; expectorants $0.6 \%$; vitamins $1 \%$. The high level of prescription of anti-psychotics and anti-depressants confirms the clinical picture of a minor population with mood/affect disorders and/or psychotic disorders.

\section{$\underline{\text { Positive outcomes after ECT }}$}

A high level of reported positive outcomes would be expected from this multiple case sample and meta-analysis. By definition, published work is often focused on atypical cases with unusual/exceptional presentations or outcomes (Miles \& Huberman, 1994). In this publishing climate, reports of case material with unusually favourable outcomes are more probable, due to a publication pressure to report positive findings. Hence, this sample of published cases reflects an inherent bias toward more positive outcomes after ECT administration.

Inspection of the data confirms that psychiatrists have observed and reported major behavioural changes after ECT administration with minors. The attribution of positive outcomes to ECT may be misleading, however, in the context of mood disorders and psychotic disorders, where extreme behaviours oscillate around the normal range. In this context, many apparent behavioural improvements are more probably explained by straightforward regression effects (Dawes, 1986). The absence of any controlled studies, or single-case studies, with children/adolescents who have been given ECT, prevents scientific analysis.

\section{$\underline{\text { Negative outcomes after ECT }}$}

Often, ECT has been discontinued by psychiatrists who have abandoned the treatment viewing it as ineffective. An inspection of these outcome data suggests that, whatever the perceived benefits of ECT, some of the negative consequences linked to this treatment are harmful and destructive. Moreover, the administration of ECT to already-damaged children and adolescents may exacerbate an existing psychological crisis. Many minors seem trapped in a negative cycle of abuse victim/victim behaviour/further abuse/ self-destruction/self-abuse. Some children given ECT subsequently have tried to kill themselves; although no causal connection exists, some children evidently perceive ECT as a frightening and damaging experience.

Paradoxically, however, some minors are positive about ECT. Other children rationalise the treatment, perceived as unstoppable and inevitable. In extreme cases, the tolerance of ECT may be a form of self-destructive behaviour. Already-abused or damaged children may perceive themselves as ready candidates for a treatment often viewed as a 'punishment'. Staff, moreover, may become enmeshed in this destructive cycle of institutionalised abuse.

\section{$\underline{\text { Side-effects after ECT }}$}

The most frequently documented side-effects after ECT administration include memory impairment and disorientation of time/place/person. Whether the side-effects of ECT 
administration are permanent remains a matter of considerable debate. In general, the search for reliable and valid information about side-effects from ECT administration has been impeded by a pervasive lack of clinical commitment to collect these data.

\section{$\underline{\text { Some speculative comments }}$}

In the 1990s, ECT remains a popular treatment for child/adolescent problems (Barker \& Baldwin, 1990; Oxlad \& Baldwin, 1995); in the United States it is estimated that up to 3500 minors are given ECT each year (Thompson \& Blaine, 1987). The present study provides an overview of published accounts of ECT administration to minors, based on a multiple case sample and meta-analysis. Hence, although there are clear limits to generalisability and representativeness, these data are truly revealing about the practices of psychiatrists who have published their clinical experiences.

An analysis of these data confirms that at least in these instances, ECT was used as 'treatment of choice', not a 'treatment of last resort'. Thus, although many children and adolescents had been given pharmacological therapies (often anti-depressants and/or anti-psychotics) few had received other psycho-therapeutic approaches. None had received a range of alternative treatments. In these published cases, at least, ECT was perceived as a beneficial 'treatment of choice', not a 'treatment of last resort'. Also, in these 217 cases only six times was psychotherapy offered as a treatment option, either before or after ECT.

The theme of consent remains central wherever ECT is given to minors. In these 217 cases, consent was mentioned eight times and was not reported in 209 cases. Whether valid or informed consent is even possible when ECT is given to minors has already been the subject of considerable debate (Barker \& Baldwin, 1990; Baldwin \& Jones, 1990, 1991; Oxlad \& Baldwin, 1995).

Examination of the presenting behaviours (PB) confirms that ECT was considered appropriate for a very wide range of conditions. Moreover, many of the presentations of these minors would be considered by many clinicians to be in the 'normal developmental' range, and appropriate forms of behavioural expression. In addition to the wide range of presenting behaviours, the volume (436) suggests (at least) diagnostic over-inclusivity by psychiatrists.

Many psychiatrists have justified the use of ECT with minors as a 'treatment of last resort' in lifethreatening circumstances. Inspection of these 217 cases produced scant instances of ECT used to save life. In only three instances had suicide been attempted by the minor; two other instances of 'suicidal tendencies' were documented. In one instance 'suicidal intent' was mentioned. 'Suicidal thoughts' were reported in four cases. One child/adolescent was 'concerned about suicide'. Hence in only 11/217 (5\%) instances was suicide mentioned in the case presentations, and on only three occasions had suicide been attempted. From this analysis the justification of ECT as a 'life-saver' is disconfirmed.

\section{Conclusion}


In sum, the use of ECT with minors as an effective, life-saving 'treatment of last resort' used when other therapies have failed, is not supported by the data from the present sample of 217 cases. In a therapeutic environment where many 'tried and tested' alternatives exist for childhood/adolescent disorders, the continued administration of ECT to minors is, at least, paradoxical.

Examination of the present multiple case sampling and meta-analysis highlights the chronic under-reporting of this form of treatment with minors. Although Thompson \& Blaine (1987) maintain that between 500 and 3500 minors receive ECT treatment each year in the United States of America alone, the present comprehensive analysis could only locate 217 published cases between 1947 and 1994.

\section{$\underline{\text { Acknowledgements }}$}

This paper is dedicated to all children and adolescents who have been given ECT.

Reprints from: Steve Baldwin, Department of Psychology, Edith Cowan University, Robertson Drive, Western Australia 6230. Tel: 09780 7777; Fax: 097216994.

Table 1: Frequency data- ages of recorded cases

$\begin{array}{lrc}\text { Age (years) } & \begin{array}{c}\text { Number of cases } \\ \text { (other studies) }\end{array} & \begin{array}{c}\text { Number of cases } \\ \text { (Bender, 1947) }\end{array} \\ 1 & -- & -- \\ 2 & -- & -- \\ 3 & -- & -- \\ 4 & -- & 1 \\ 5 & 4 & 10 \\ 6 & 2 & 10 \\ 7 & 4 & 10 \\ 8 & 1 & 16 \\ 9 & 3 & 17 \\ 10 & 6 & 17 \\ 11 & 6 & 17 \\ 12 & 11 & -- \\ 13 & 12 & -- \\ 14 & 20 & -- \\ 15 & 19 & -- \\ 16 & 10 & -- \\ 17 & 13 & -- \\ 18 & 8 & -- \\ & & \end{array}$

Table 2: Diagnostic data -- diagnostic criteria

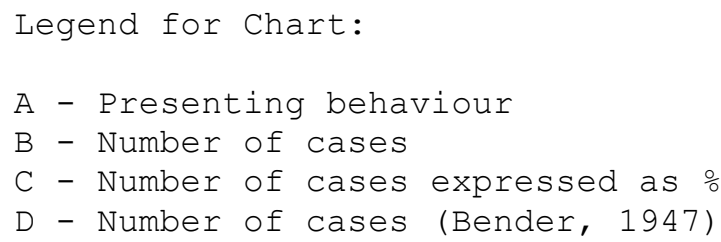


A

Withdrawn
Somatic complaints
Anxious/depressed
Social problems
Thought problems
Attention problems
Delinquent behaviour
Aggressive behaviour
Other problems
B

30

16

36

7

37

25

7

7

42
C

12.7

6.8

15.2

3.0

15.6

10.5

3.0

15.6

17.7
D

98

$--$

98

98

98

98

$--$

98

Table 3: Clinical data -- presenting behavior [Without Bender (1947)]

$\begin{array}{lr}\text { Presenting behaviour } & \text { Frequency } \\ \text { Withdrawn } & 65 \\ \text { Somatic complaints } & 19 \\ \text { Anxious/depressed } & 70 \\ \text { Social problems } & 10 \\ \text { Thought problems } & 112 \\ \text { Attention problems } & 52 \\ \text { Delinquent behaviour } & 12 \\ \text { Aggressive behaviour } & 97 \\ \text { Other problems } & 197\end{array}$

Table 4: Clinical data -- summary of published accounts of ECT administration by decade

$\begin{array}{lrrrrr}\text { Decade } & \mathrm{n} & \begin{array}{c}\text { Number of } \\ \text { treatments }\end{array} & \begin{array}{c}\text { Mode } \\ \text { Bi-lat. }\end{array} & \begin{array}{c}\text { Mode } \\ \text { Uni-lat }\end{array} & \begin{array}{c}\text { Mode } \\ \text { Unspec. }\end{array} \\ 1940-49 & 127 & 2294 & 29 & 0 & 98 \\ 1950-59 & 21 & 174 & 0 & 0 & 21 \\ 1960-69 & 15 & 124 & 0 & 0 & 15 \\ 1970-79 & 8 & 64 & 0 & 0 & 8 \\ 1980-89 & 25 & 223 & 18 & 31 & 11 \\ 1990-94 & 21 & 154 & 2 & 3 & 9 \\ \text { Total } & 217 & 3033 & 49 & 34 & 162\end{array}$

Table 5: Clinical data -- drug therapies

$\begin{array}{lr}\text { Drug type } & \text { Frequency } \\ \text { Antihypertensives } & 3 \\ \text { Hypnotics } & 11 \\ \text { Anxiolytics } & 1 \\ \text { Antipsychotics } & 71 \\ \text { Antidepressants } & 70 \\ \text { Anticonvulsants } & 2 \\ \text { Movement disorders } & 6 \\ \text { CNS stimulants } & 1 \\ \text { Migraine treatments } & 1 \\ \text { General anaesthetics } & 1 \\ \text { Expectorants } & 1\end{array}$


Table 6: Clinical data -- response to drug therapies
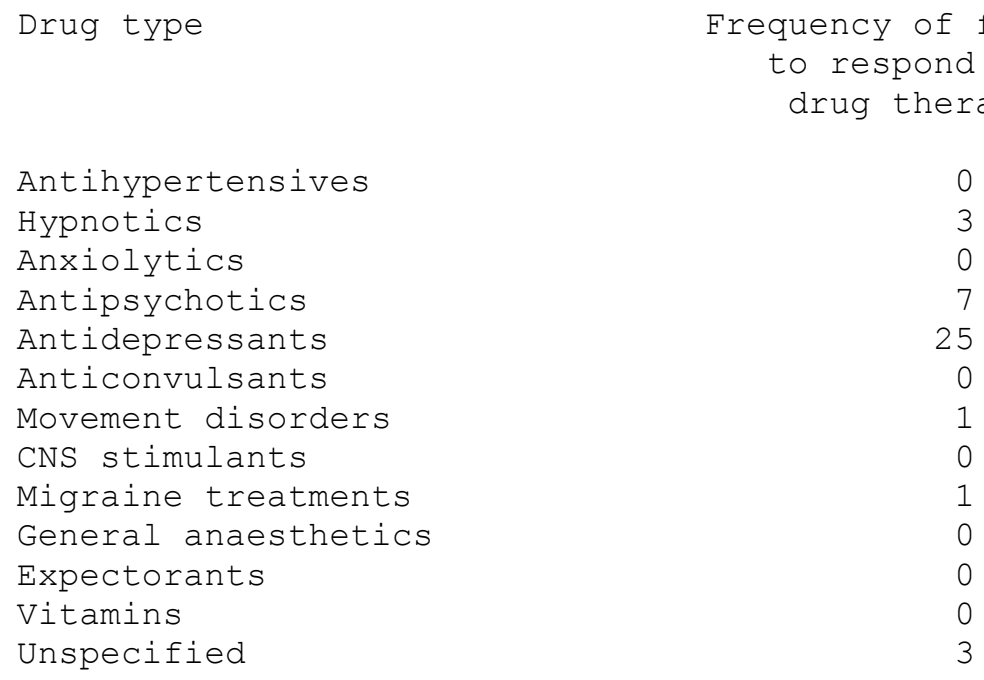

Table 7: Clinical data -- summary of outcomes

$\begin{array}{lcccc}\begin{array}{l}\text { Presenting } \\ \text { behaviour }\end{array} & \begin{array}{c}\text { Positive } \\ \text { outcomes }\end{array} & \begin{array}{c}\text { Negative } \\ \text { outcomes }\end{array} & \begin{array}{c}\text { Positive } \\ \text { outcomes } \\ \text { (Bender, } \\ 1947 \text { ) }\end{array} & \begin{array}{c}\text { Negative } \\ \text { outcomes } \\ \text { (Bender, } \\ 1947 \text { ) }\end{array} \\ \text { Withdrawn } & & & 0 & 98 \\ \text { Somatic complaints } & 1 & 5 & 0 & 0 \\ \text { Anxious/depressed } & 4 & 3 & 0 & 98 \\ \text { Social problems } & 0 & 13 & 0 & 98 \\ \text { Thought problems } & 8 & 1 & 0 & 98 \\ \text { Attention problems } & 0 & 16 & 0 & 98 \\ \text { Delinquent behaviour } & 2 & 5 & 0 & 0 \\ \text { Aggressive behaviour } & 17 & 0 & 0 & 0 \\ \text { Other problems } & 53 & 25 & 98 & 98 \\ \text { References } & & 32 & & \end{array}$

Abrams, R. (1988) Electroconvulsive Therapy. 1st Ed. New York, Oxford University Press.

Achenbach, T. M. \& Edelbrock, C. (1991) Manual for the child behavior checklist. Burlington, University of Vermont, Department of Psychiatry.

Baldwin, S. \& Jones, Y. (1990). ECT, children and clinical psychologists. Clinical Psychology Forum, 16, 2-4.

Baldwin, S. \& Jones, Y. (1991) More ECT, more children and more clinical psychologists. Clinical Psychology' Forum, 31, 13-15.

Barker, P.J. \& Baldwin, S. (1990) Shock story. Nursing Times, 8, 30-39. 
Bender, L. (1947) One hundred cases of childhood schizophrenia treated with electric shock. Transactions of the American Neurological Association, 72, 165-169.

Cerletti, U. \& Bini, L. (1940) Le alterazioni istopatologiche del sistema nervosa nell 'Elettroshock'. Rivista Sperimentale di Freniatria, 64, 311-359.

Dawes, R. M. (1986) Representative thinking in clinical judgement. Clinical Psychology Review, 6, 425-441.

Fink, M. (1990) Electroconvulsive therapy. Current Opinion in Psychiatry, 3, 58-61.

Heuyer, P.G., Dauphin, M. \& Lebovici, S. (1947) La pratique de l'electrochoc chez l'enfant. Acta Paedopsychiatrica, 14, 60-64.

McMahon, M. (1990) Net-widening: vagaries in the use of a concept. British Journal of Criminology, 30, 121-149.

Miles, M.B. \& Huberman, A.M. (1994) Qualitative data analysis. 2nd edn. Thousand Oaks, California, Sage.

Oxlad, M. \& Baldwin, S. (1995) Electroconvulsive therapy, children and adolescents: the power to stop. Nursing Ethics, 2, 333-346.

Thompson, J.W., Blaine, J.D. (1987) Use of ECT in the United States in 1975 and 1980. American Journal of Psychiatry, 144, 557-562.

\section{$\underline{\text { APPENDIX } 1}$}

Reference list for the original papers used in this multiple case sampling and meta-analysis.

Andrade, C., Gangadhar, B.N., Swaminath, G. \& Channabasavanna, S.M. (1990) Further characterisation of mania as a side-effect of ECT. Convulsive Therapy, 6(4), 318-319.

Baker, T. (1994) ECT and young minds. Lancet, 345, 65.

Baldwin, S. \& Jones, Y. (1990) ECT, children and clinical psychologists: A shock to the system. Clinical Psychology, Forum, 16, 2-4.

Bender, L. (1947) One hundred cases of childhood schizophrenia treated with electric shock. Transactions of the American Neurological Association, 72, 165-169.

Bender, L. \& Keeler, W.R. (1952) The body image of schizophreic children following electroshock therapy. American Journal of Orthopsychiatry, 22, 335-355. 
Berman, E. \& Wolpert, E.A. (1987) Intractable manic-depressive psychosis with rapid cycling in an 18-year-old woman successfully treated with electroconvulsive therapy. Journal of Nervous and Mental Diseases, 175, 236-239.

Bertagnoli, M.W. \& Borchardt, C.M. (1990) A review of ECT for children and adolescents. Journal of American Academy of Child and Adolescent Psychiatry, 29, 302-.

Black, D.W., Wilcox, D.O. \& Stewart, M. (1985) The use of ECT in children: Case report. Journal of Clinical Psychiatry, 46, 98-99.

Campbell, J.D. (1952) Manic depressive psychosis in children: Report of 18 cases. Journal of Nervous and Mental Diseases, 116, 424-439.

Campbell, M. (1973) Biological interventions in psychoses of childhood. Journal of Autism and Childhood Schizophrenia, 3, 347-373.

Carr, V., Dorrington, C., Scrager, G. \& Wale, J. (1983) The use of ECT for mania in childhood bipolar disorder. British Journal of Psychiatry, 143, 411-415.

Clardy, E.R. \& Rumpf, E.R. (1954) The effect of electric shock on children having schizophrenic manifestations. Psychiatric Quarterly, 28, 616-623.

Collins, M.N. \& Jacobson, R.R. (1990) Changing interactions between bipolar affective disorder and anoxic brain damage. British Journal of Psychiatry, 156, 736-740.

Cook, A. \& Scott, A. (1992) ECT for young people. British Journal of Psychiatry, 161, 718-719.

Deshmukh, D.K., Joshi, V.S. \& Agarwal, M.R. (1989) Neuroleptic malignant syndrome: Report of 2 cases. Indian Journal of Psychiatry, 31(1), 90-92.

Devinsky, O. \& Duchowny, M.S. (1983) Seizures after convulsive therapy: A retrospective case survey. Neurology, 33(7), 921-925.

Frances, A. \& Susman, V.L. (1986) Managing an acutely manic 17-year-old girl with neuroleptic malignant syndrome. Hospital and Community Psychiatry, 37(8), 771-788

Frommer, E.A. (1968) Depressive illness in childhood. In: Coppen, A. \& Walk, A. (eds). Recent developments in affective disorders: A symposium. British Journal of Psychiatry (special publication, No. 2), 117-136.

Gallinek, A. (1952) Controversial indications for electric convulsive therapy. pp361-366.

Gillis, A. (1955). A case of schizophrenia in childhood. pp.471-472.

Guttmacher, L.B. \& Cretella, H. (1988) Electroconvulsive therapy in one child and three adolescents. Journal of Clinical Psychiatry, 49, 20-23. 
Guttmacher, L.B., Cretella, H. \& Houghtalen, R. (1989) Dr. Guttmacher and colleagues reply. Journal of Clinical Psychiatry, 50, 106-107.

Hassanyeh, F. \& Davison, K. (1980) Bipolar affective psychosis with onset before age 16 years: report of 10 cases. British Journal of Psychiatry, 137, 530-539.

Heuyer, P.G., Dauphin, M. \& Lebovici, S. (1947) La pratique de l'electrochoc chez l'enfant. Acta Paedopsyciatrica, 14, 60-64.

Hift, V.E., Hift, S.T. \& Spiel, W. (1960) Ergebnisse der schockbehandlungen bei kindlichen schizophrenien. Aus der psychiatrisch-neurologischen klinik der universitatwien, 256-272.

Idupuganti, S. \& Mujica, R. (1988) Hemifacial flushing during unilateral ECT. American Journal of Psychiatry, 145, 1037-1038.

Jeffries, J.J. \& Lefebvre, A. (1973) Depression and mania associated with Kleine-LevinCritchley Syndrome. Canadian Psychiatric Association Journal, 18, 439-444.

Kastenbaum, C.J. (1976) Childhood schizophrenia -- late onset. In: B. Wolman, Handbook of Child Behaviour Therapy, pp.367-369.

Mankanjuola, J.D. \& Oyerogba, K.O. (1987) Management of depressive illness in a Nigerian neuropsychiatric hospital. Acta Psychiatrica Scandinavia, 76, 486-489.

Mansheim, P. (1983) ECT in the treatment of a depressed adolescent with meningomyelocele, hydrocephalus, and seizures. Journal of Clinical Psychiatry, 44, 385-386.

McCabe, M.S. (1976) ECT in the treatment of mania: A controlled study. American Journal of Psychiatry, 133, 688-691.

Ohaeri, J.U., Hedo, C.C., Enyidah, S.N. \& Ogunniyi, A.O. (1992) Tissue injury-inducing potential of unmodified ECT: Serial measurement of acute phase reactants. Convulsive Therapy, $8,253-257$.

Paillere-Martinot, M.L, Zivi, A. \& Basquin, M. (1990) Utilisation de l'ECT chez l'adolescent. L'Encephale, XVI, 399-404.

Pippard \& Ellam (1981) Audit of ECT in Great Britain. London

Powell, J.C., Silveira, W.R. \& Lindsay, R. (1988) Pre-pubertal depressive stupor: A case report. British Journal of Psychiatry, 153, 689-692.

Rosen, A. (1979) Case report: Symptomatic mania and phencyclidine abuse. American Journal of Psychiatry, 136, 118-119. 
Rosen, A.M., Mukherjee, S. \& Shinbach, K. (1984) The efficacy of ECT in Phencyclidineinduced psychosis. Journal of Clinical Psychiatry, 45, 220-222.

Sands, D. (1978). Acute psychotic disturbance and regression in an adolescent girl. Nursing Times, 14, 2055-2057.

Schneekloth, T. D., Rummans, T. A. \& Logan, K.M. (1993). Electroconvulsive therapy in adolescents. Convulsive Therapy, 9, 158-166.

Sokol, M.S., Pfeffer, C.R., Soloman, G.E., Esman, A., Robinson, G., Gold, R.L. \& OrrAndrawes, A. (1989) An abused psychotic adolescent at risk for Huntington's Disease. Journal of American Academy of Child and Adolescent Psychiatry, 28, 612-617.

Warneke, L. (1975) A case of manic-depressive illness in childhood. Canadian Psychiatric Association Journal, 20, 195-200.

Warren, A.C., Holroyd, S. \& Folstein, F. (1989) Major depression in Down's Syndrome. British Journal of Psychiatry, 155, 202-205.

\section{By STEVE BALDWIN \& MELISSA OXLAD}

Edith Cowan University, Western Australia \& University of South Australia, Australia 